\title{
Spirituality and Ubuntu as foundation for building African institutions, organizations and leaders
}

DOI:

10.1080/14766086.2016.1159976

\section{Document Version}

Accepted author manuscript

Link to publication record in Manchester Research Explorer

\section{Citation for published version (APA):}

Mamman, A., \& Bukari Zakaria, H. (2016). Spirituality and Ubuntu as foundation for building African institutions, organizations and leaders. Journal of Management, Spirituality \& Religion.

https://doi.org/10.1080/14766086.2016.1159976

\section{Published in:}

Journal of Management, Spirituality \& Religion

\section{Citing this paper}

Please note that where the full-text provided on Manchester Research Explorer is the Author Accepted Manuscript or Proof version this may differ from the final Published version. If citing, it is advised that you check and use the publisher's definitive version.

\section{General rights}

Copyright and moral rights for the publications made accessible in the Research Explorer are retained by the authors and/or other copyright owners and it is a condition of accessing publications that users recognise and abide by the legal requirements associated with these rights.

\section{Takedown policy}

If you believe that this document breaches copyright please refer to the University of Manchester's Takedown Procedures [http://man.ac.uk/04Y6Bo] or contact uml.scholarlycommunications@manchester.ac.uk providing relevant details, so we can investigate your claim.

\section{OPEN ACCESS}


DOI: $10.1080 / 14766086.2016 .1159976$

Journal: Journal of Management, Spirituality \& Religion

Manuscript ID: 1159976

\section{File Correction Details}

No Correction Found

Online Correction Link : http://tandfproof.sps.co.in:8080/oxe_tf_v3/index.php?token=ibAKTcrGH34kFW7T41 hdAj4-

SImDsqugKcA9XVR5DrNOXi2smcMRLCOu72p9M07

\section{Image Annotation Details}

No Details Found

\section{Attached File Details}

No Details Found

\section{List of Comments}

No comments found

\section{Query Details}

1. Please provide missing country for the affiliation ' $a$ '.

United Kingdom

2. Please provide missing department for the affiliation ' $b$ '.

School of Public Service and Governance

3. Please provide keywords.

African Leadership; Institution Building; Management Development; Spirituality, Ubuntu

4. Please check that the heading levels have been correctly formatted throughout.

Resolved in text

5. The reference "Zohar, 1997" is cited in the text but is not listed in the references list. Please either delete intext citation or provide full reference details following journal style [hyperlink to relevant style-sheet].

Please delete Zohar, 1997 from the text.

6. The spelling of Edwards for "1999" has been changed Emmons 1999 to match the entry in the references list. Please confirm that this is correct and provide revisions if needed I can confirm this is correct. Thank you

7. Please check the edit made in the sentence "This is in tune with the argument ..." and correct if necessary. Yes the editing is correct. Thank you. 
8. The Year for "Goleman 2002" has been changed Goleman 2006 to match the entry in the references list. Please confirm this is correct and provide revisions if needed.

Yes I can confirm this is correct. Thank you

9. Please provide the Notes on contributors (regarding current academic position, research interests, books/articles published).

Aminu Mamman is a Reader in Human Resource Mangement and International Managment, Institute of Development Policy and Management, University of Manchester, UK. His research focuses on Management and Leadership in Developing countries, and the diffusion and application of management ideas across developed and developing countries. He has published in reputable journals such as Organization Studies, British Journal of Management, Human Resource Manageement Review; and International Journal of Human Resource Management. His latest book (SMEs and Poverty Reduction in Africa) argues for the use of Spirituality to develop entrepreneurs in Africa.

Hamza Zakaria is currentlya Lecturer at the School of Public Service and Governance, Ghana Institute of Management and Public Administration (GIMPA). His research focuses on Decentralization and Local Government Administration, Performance Management, Leadership, Public Administration and Public Management. Hamza has published in the Public Administration and Development, Public Organisation Review and in the International Journal of Public Administration

10. The CrossRef database (www.crossref.org/) has been used to validate the references. Mismatches between the original manuscript and CrossRef are tracked in red font. Please provide a revision if the change is incorrect. Do not comment on correct changes.

The revision is correct. Thank you,

11. Please provide missing city for the "Ciarrochi, 2007" references list entry.

The missing city is New York.

12. Please provide missing last page numbers for the "Damanee, 2001" references list entry.

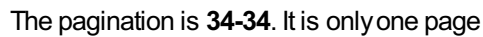

13. Please provide missing last page numbers for the "Deng, 1998" references list entry.

The pagination is Page 1-11.

14. Please provide missing last page numbers for the "Emmons, 2000" references list entry.

The details should read as follows

International Journal for the Psychology of Religion 10 (1): 3-26

15. Please provide missing city for the "Gano-Overway, 2014" references list entry.

The City is London

16. Please provide missing city for the "Goleman, 2006" references list entry.

This City is New York

17. Please provide missing city for the "King, 1990" references list entry.

The City is New York

18. Please provide missing city for the "Mbiti, 1991" references list entry.

The City is New Hampshire

19. Please provide missing year of publication for the "Pavlovich and Krahnke eds." references list entry.

The missing date is 2013

20. Please provide missing publisher for the "World Bank, 2009" references list entry.

The publisher is: The International Bank for Reconstruction and Development/World Bank

21. Please provide missing publisher for the "World Bank, 2013" references list entry.

The publisher is: The International Bank for Reconstruction and Development/World Bank 



\title{
Spirituality and Ubuntu as foundation for building African institutions, organizations and leaders
}

Running heads:

Journal of Management, Spirituality \& Religion

A. Mamman and H. B. Zakaria

Mamman Aminu a *

Zakaria Hamza B. b

AQ1 ${ }^{a}$ The University of Manchester, Institute for Development Policy and Management, Manchester

AQ2 ${ }^{b}$ GIMPA School of Public Service and Governance (GSPSG), Accra, Ghana

Corresponding author.Email: aminu.mamman@manchester.ac.uk

Received 01 Jul 2015; Accepted 22 Jan 2016

(C) 2016 Association of Management, Spirituality \& Religion

\begin{abstract}
It is widely argued that institutions and organizations are the building blocks of modern societies. However, African nations are characterized by an institutional void and ineffective organizations. In fact, even the effectiveness of informal institutions such as customs and traditions is now debatable. Therefore, this paper sets out to provide a novel approach for building effective organizations, leaders and people based on the foundation of spirituality and African philosophy of Ubuntu. We coupled the concepts of spirituality and Ubuntu and advanced a framework and techniques to guide the development of African organizations and its people. We have provided theoretical and practical rationale for the use of spirituality and Ubuntu to augment the Western-based modern approach to managing organizations and its people.
\end{abstract}

\section{Introduction}

AQ3 $\quad$ AQ4

As the social and economic conditions of African societies continue to deteriorate, many observers argue that the solution lies in developing good governance systems and framing appropriate policies to match (Africa Commission Report 2005; Chabal 2002; Deng and Lyons 1998; Turner, Hulme, and McCourt 2015). This paper argues that while good governance is undoubtedly the key to addressing the social and economic challenges in Africa, the notion that we can have good governance systems without good governors is a theoretical dream. Several attempts have indeed been made to establish governance systems alongside what appear to be good policies. However, the evidence suggests that the outcome of such efforts is increasing corruption, inequality and poverty, as manifested in most countries on the continent (World Bank 2009, 2013). The social and ethnic conflicts ravaging many countries in the region have their root in poor governors and sometimes in inappropriate policies. We argue in this paper that simply identifying the social and economic challenges and their causes is a no-brainer; finding effective solutions to the problems, however solutions which lie outside the conventional approaches - is another thing altogether.

We advance the argument that the solution to the core problems facing many African countries today requires thinking outside the box. In brief, it requires creative thinking. We argue that the regulatory institutions and agencies or organizations mandated to implement national and regional policies need to be transformed according to a new paradigm. Similarly, governors (i.e. policy-makers) and those who implement policies need to be reoriented and transformed via this new paradigm. And the paradigm must be compatible with the African mindset and psyche (Africa Commission Report 2005). Our central argument is that if the limitations of the extant governance systems (i.e. institutions and agencies) and the governors are eradicated, the likelihood of eradicating the social and economic challenges will be enhanced.

This creative approach to addressing Africa's social and economic challenges should focus on nurturing and developing the right people, and these people should then go on to inhabit the governance structures and systems. In particular, there should be a focus on the leaders and future leaders, policy-makers, and policy implementers. Secondly, the approach we advocate for nurturing and developing such people should lie outside the conventional approach, which has proved inadequate to tame the undesirable behavior of policy-makers and implementers. This means, for example, that the philosophical foundations of institutions, agencies, and leadership should be based on a new paradigm. In addition, there should be built-in incentives and reinforcement mechanisms which will favor the application of the skills, knowledge, and values acquired from leadership development programs. Thirdly, the philosophical foundation for nurturing and developing policy-makers and leaders should have its roots in the African cultural traditions, as are 
manifested in the thinking and behavior of people.

Therefore, the objectives of this paper are to provide guidelines on how to bridge the gaps between: (1) what institutions and agencies are set up for and what they do; (2) how Africans behave and how they are expected to behave as policy-makers and implementers; and; (3) how African policymakers and implementers are developed and how they should be developed within the context of the African socio-economic environment; (4) what African policy-makers and implementers know and the motivation to apply what they know. The following sections provide brief literature on the concepts of spirituality and Ubuntu. We will demonstrate how the two concepts overlap and therefore reinforce each other which provide the rationale for using them as safe and neutral instruments for developing people in a multi-ethnic and multi-religious context of Africa.

\section{Ubuntu as philosophy}

According to Nussbaum $(2003$, 2), Ubuntu is a 'fountain from which actions and attitudes flow". Ubuntu can be described as a belief system, since belief has been argued to influence attitudes and behavior (Damane 2001). Ubuntu is also viewed as an African philosophy of life as demonstrated by the following statements: "A person is a person because of others"; Ubuntu is the quality of being human"; "It is through others that one attains selfhood"; 'I am because we are, and since we are, therefore I am” (Mbiti 1991; Nussbaum 2003). Swanson (2007, 55) is more affirmative in the description of Ubuntu as a philosophy. As Swanson puts it: 'Ubuntu is recognized as the African philosophy of humanism, linking the individual to the collective through "brotherhood" or "sisterhood". It makes a fundamental contribution to indigenous "ways" of knowing and being". The author also adds a personal view to the understanding of Ubuntu when he asserts: "As I have grown to understand the concept, Ubuntu is borne out of the philosophy that community strength comes of community support, and that dignity and identity are achieved through mutualism, empathy, generosity, and community commitment'(Swanson 2007, 55).

The notion of connectedness in the philosophy of Ubuntu is in line with the concept of Empathy advanced by experts (see Pavlovich and Krahnke 2012). One of the earlier writers on Ubuntu (Mbigi 1997) views Ubuntu as African world view steeped in the notion or doctrine of communalism. It is the foundation or the roots and stem on which behavioral principles and practices manifest themselves. Hence, Mbigi (1997) used the analogy of a tree and its branches to explain the concept of Ubuntu and its manifestation. According to Mbigi (1997), while Ubuntu represents the stem, the branches are represented by communal enterprise, leadership legitimacy, value sharing, collectivism and solidarity, continuous integrated development, interconnectedness, and respect and dignity. Many of these elements are found in the concept of spirituality and system thinking.

For others, Ubuntu is a philosophical thought system (Damane 2001). However, the thought system is valued for its instrumental contribution to judgment and decision-making. As Damane $(2001,24)$ argues, "Whether it is a critical issue that needs to be interpreted or a problem that needs to be solved, Ubuntu is invariably invoked as a scale for weighing good vs. bad, right vs. wrong, just vs. unjust". Thus, as we argued earlier, if one sees Ubuntu as a belief system, such a belief system can influence behavior. In fact, Damane (2001) demonstrated how a company in South Africa used the African belief system to extract a confession from an employee engaged in pilfering. Others who subscribe to Ubuntu as a philosophy include Samkange and Samkange (1980), Sibanda (2014), Kamalu (1990), Ramose (1999), Dzobo (1992) and Crick (1999). Central to the argument that Ubuntu is a philosophy is the view that humanness is the most noble ideal to be aspired by an African (Nziramasanga 1999). In other words, Ubuntu is a philosophy of viewing the world that defines an African through his community. In fact, one argument states that it is the community that bestows humanness upon an individual or withholds it (Makuvaza 1996; Sibanda 2014). This prompts critiques to argue that Ubuntu is disempowering individual self-determination and integration with the wider world in this era of globalization. However, this criticism is countered by several advocates of Ubuntu (e.g. Gyekye 1996; Lutz 2009; Obiora and Edozien 2001). As Lutz (2009, 1) points out:

The communal character of African culture does not mean, however, that the good of the individual person is subordinated to that of the group, as is the case with Marxist collectivism. In a true community, the individual does not pursue the common good instead of his or her own good, but rather pursues his or her own good by pursuing the common good. The ethics of a true community does not ask persons to sacrifice their own good in order to promote the good of others, but instead, to recognise that they can attain their own true good only by promoting the good of others.

In support of critics, noble as the Ubuntu philosophy is, many African policy-makers do not live up to the philosophy as evidenced by the rampant corruption ravaging the economy and the societies. However, the above quotation by Lutz (2009) provides a practical avenue to operationalize Ubuntu in an institutional and organizational setting. As we will demonstrate later, to fully achieve the objective of transforming African institutions and organizations, people need to see the real or potential individual benefits that will accrue from the change in attitudes and behavior through Ubuntu and spirituality. We advocate the use of spirituality and Ubuntu not as moral or feel-good crusade, but as an instrumental strategy to improve the effectiveness of individuals, organizations, institutions and the wider society. 
Like most philosophies, Ubuntu has guiding principles and behavioral expectations. For example, since Ubuntu is predicated on the idea of humanness, there should be guiding principles regarding how to be human. To be human, according to Ubuntu theorists, one has to appeal to the heart and spirit, rather than rational reasoning (July 2004; Sibanda 2014). To be human is to be upright, respectable and respected (Nziramasanga 1999). More specifically, humanness is supposed to be expressed through discipline, morality, altruism, self and social consciousness, responsibility and duty (Sibanda 2014, 27). The principles that underpin Ubuntu are outlined further by one of the earlier proponents of the concept (Mbigi 1997). Mbigi (1997) highlighted the following as the salient principles of Ubuntu: the spirit of unconditional collective contribution, solidarity, acceptance, dignity, stewardship, compassion and care. Other underlying principles of Ubuntu include fairness, interconnectedness, consensus, trust, shared understanding, harmony, respect and justice (Nussbaum 2003 ). Lutz (2009) also highlighted some of the overlapping principles of Ubuntu as generosity, hospitality, friendliness, caring and compassion. How are these expressed, or supposed to be expressed in daily behavior, since Ubuntu is supposed to guide daily action in any relationship? Metz (2007) has identified six behavioral principles in his synthesis of the definitions of Ubuntu as a moral theory.

U1: An action is right just insofar as it respects a person's dignity; an act is wrong to the extent that it degrades humanity.

U2: An action is right just insofar as it promotes the well-being of others; an act is wrong to the extent that it fails to enhance the welfare of one's fellows.

U3: An action is right just insofar as it promotes the well-being of others without violating their rights; an action is wrong to the extent that it either violates rights or fails to enhance the welfare of one's fellows without violating rights.

U4: An action is right just insofar as it positively relates to others and thereby realizes oneself, an act is wrong to the extent that it does not perfect one's valuable nature as a social being.

U5: An action is right just insofar as it is in solidarity with groups whose survival is threatened; an act is wrong to the extent that it fails to support vulnerable communities.

U6: An action is right just insofar as it produces harmony and reduces discord; an act is wrong to the extent that it fails to develop community (Metz 2007, 328).

All the six characterizations of Ubuntu are supposed to guide behavior. However, according to Metz (2007), U4 and U6 are better reflections or characterizations of the concept because as he states:

... a better fundamental explanation of why I ought to help others appeals not to the fact that it would (likely) be good for me, or at least not merely to this fact, but to the fact that it would (likely) be good for them. (Metz 2007, 330)

In spite of the virtues of Ubuntu philosophy and principles, given the state of African institutions (formal and informal) and organizations, and indeed the wider societies, there is clear evidence from all indices that collectively, individuals are not living up to the philosophy and principles of Ubuntu. While we submit that the true ideals of humanness can never be attained except by a saint, the application of some of the principles by a critical mass of people at organizational, institutional and societal levels will make a huge positive difference to the state of African socioeconomic conditions. Therefore, we argue for the integration of Ubuntu philosophy and principles into the development of organizations and its members. This should be done in conjunction with the principles of spirituality and modern management. In fact, many writers advocate the use of Ubuntu in managing modern organizations and institutions (see Karsten and Illa 2005; Lutz 2009; Mangaliso 2001; Mbigi 1997; Nkondo 2007; Nussbaum 2003; Swanson 2007). The following statements by Nkondo (2007) about the potential applications of Ubuntu is instructive: "What has to be learned in Ubuntu is not a doctrine such as 'the wages of sin are death", nor is it a rule such as 'the truth will free you'; but how to live humanely with others in a given space and time. It is not a device for instrumental formulation of judgement, but a social practice in terms of which to think, to choose, to act and to speak" (Nkondo 2007, 93).

Mangaliso (2001) argued that Ubuntu principles can be used to build competitive advantage for business organizations, especially in building relationships, communication, decision-making, productivity and leadership. The author provided the following guidelines for the implementation of Ubuntu philosophy in organizations: Treating others with dignity and respect; Negotiating in good faith at all times; providing opportunities for selfexpression; Understanding the beliefs and practices of others; Honoring seniority in leadership choices; Promotion of equality in the workplace; Flexibility and accommodation between Western principles and Ubuntu principles (Mangaliso 2001, 32).

Many writers have advocated the application of Ubuntu as an instrument of public policy (Bengu 1998; Nkondo 2007; Shutte 2001). Nkondo $(2007,95)$ argues that Ubuntu can be used to build a foundation for specific public policy because the philosophy

seeks to reconcile the idea that the society possesses a morally privileged status that should be enshrined and protected by certain inviolable rights and freedom against exploitation and domination. Second, the idea that the rights and freedoms of the individual and personal ownership should not be in 
conflict with the common good.

Nkondo $(2007,95)$ is of the view that 'the neo-liberal claim that the market is the only mechanismand medium able to meet social requirements and the needs of the individual has had a disastrous record in Africa". Nkondo is not the only person or the first person to criticize the impact of neoliberal

AQ5 economic policy in developing countries (see Zohar 1997; Zohar and Marshall 1994, 2000 ).

For our purpose, we argue that organizations and institutions in Africa are on the most part built on the foundation of neoliberal philosophy or principles. Most significantly, the management of such institutions and organizations as well as the recruitment and development of members of such institutions and organizations are built on the foundation of neoliberal principles. In fact, the recent adoption and diffusion of New Public Management principles and practices is underpinned by neoliberal philosophy (Turner, Hulme, and McCourt 2015).

We argue that the absence of well-articulated practical alternatives to the Western neoliberal approach largely explains the persistence of neoliberal approach to building institutions and organizations in Africa. While the use of Western-based management tools and techniques are essential for managing modern public and private institutions and organizations in Africa, we argue that their use should be underpinned by the philosophy and principles of spirituality and Ubuntu. In other words, modern management principles should be regarded as technology for managing organizations where their application is guided by the philosophy of common good. In advocating the application of Ubuntu in African organizations, Lutz ( 2009, 4) argues:

When the firm is understood as a community, the purpose of management is neither to benefit one collection of individuals as shareholders - value maximization theories claim, nor to benefit several collections of individuals, as stakeholder theories tell us, but to benefit the community, as well as the communities of which it is part. In most African business schools, the doctrine that shareholder - value - maximization is the goal of management is assumed as axiomatic. In addition to being unethical, this doctrine contradicts African cultures.

Lutz $(2009$, 4) further quoted Broodryk $(2005,168)$, where he stated that:

A new culture for enterprise is needed. This culture is about striving for decent survival and working towards profit-making, but not striving for the greatest profit at all costs, especially not at the exploitation of human beings in order to attain goals characterised by greed and selfishness.

$\operatorname{Lutz}(2009$, 4) is of the view that 'to promote the good of the community is to promote the good of all members". Lutz (2009) argues that the best way to apply Ubuntu is through the decentralization of the doctrine of the common good". As he puts it, "We should attempt to promote the common good at higher levels only when it is impossible to do so at the lower levels in the organization". (p. 7). As we shall see in the following sections, Ubuntu overlaps neatly with the conceptual and philosophical approaches to spirituality.

\section{Spirituality}

Like Ubuntu, spirituality defies definition (George et al. 2000). This is partly because of its religious connotation and history. However, recently there has been significant effort to distinguish religion from spirituality. The former focuses on the sacred/divine and organized practices, while the latter focuses on the individualistic secular search for meaning and purpose (Bigger 2008). It should be pointed out that there is still a strong school of thought that insists on the need to see religion and spirituality as inseparable (Zinnabauer et al. 1997). For obvious reasons, and for practical nature of this paper, it is not our intention to delve into the merits or demerits of separating the two concepts. We acknowledge the logic of the two arguments. However, for our purpose, we adopt the secular perspective of spirituality. The first reason for doing so is because the secular perspective of spirituality fits neatly with the concept of Ubuntu. In fact, most of the literature that advocate the application of Ubuntu in organizations focus on the philosophical aspects of Ubuntu, rather than the divine and the sacred. Secondly, most of the principles of Ubuntu overlap with the concept of spiritual intelligence. We therefore adopt the following explanation of spirituality:

We need to regard spirituality as a quest for personal meaning - making at the highest level, which includes intellectual, ethical, social, political, aesthetic and other such dimensions. It makes a quality of reflection which is holistic in scope, transcends material needs and ambitions, and transforms the personality in positive ways. (Bigger 2000,3)

Like Ubuntu, spirituality has been described by Roehlkepartain et al. $(2006,139)$ as 'the essential potentiality for addressing the ultimate questions that are intrinsic to the experience of being human". Experts have argued that people who are spiritual demonstrate their ultimate concerns through the way they strive to fulfill personal goals (APTER 1985; Emmons 1999; Jaworski 1996; Pargament and Park 1995). As we highlighted earlier, Ubuntu tries to provide guiding principles that will make a person human. According to Bigger $(2008,62)$, spirituality is personal but at the same time experiential and integrative - where transcendence, morality, belonging, connectedness, meaning and purpose are all included in conception. Bigger's explanation with emphasis on belonging, connectedness and meaning further highlights the overlap between Ubuntu and spirituality. In a nutshell, spiritual people are concerned with the meaning of life and what they find meaningful. Hence they try to search and do what is meaningful. They also derive 
satisfaction from the achievement of doing what is meaningful. From Ubuntu perspective, meaning is embedded in what it is to be human which is derived through communality, connectedness and common good.

\section{Being spiritual and spiritually intelligent}

We know what it is to be human according to Ubuntu. What does it take to be spiritual? According to Bigger (2008), spirituality is a journey, therefore experiential. However, some are more categorical in their description of being spiritual or how to attain the status. According to Chaudhary and Aswal $(2013$, 1510), "to be spiritual is to think, act and interact from an awareness of self as spirit not form". To be spiritual is to be spiritually intelligent (Chaudhary and Aswal 2013). To be able to develop spiritual intelligence, one needs to have the characteristics of spiritually intelligent people. In other words, how would you know that a person is spiritually intelligent? Zohar (2005) provided some indications of the answer to this question. According to Zohar, spiritually intelligent people can be distinguished by the following characteristics: self-awareness; spontaneity; being vision and value led; compassion; holism; celebration of diversity; field independence; humility; urge to ask why question; ability to reframe; positive use of adversity; sense of vocation. This means that these characteristics can be the foundation for developing training and development curriculum for policy-makers and public servants in Africa. We will return to this point later.

AQ6 According to Edwards (Emmons 1999), spiritual intelligence is a way of thinking that everyone is born with it. Similarly, Zohar and Marshall $(2000,22)$ argues that spiritual intelligence

is what we use to develop our longing and capacity for meaning, vision and value. It facilitates a dialog between reason and emotion, between mind and body. It allows us to integrate the intrapersonal and the interpersonal, to transcend the gap between self and other.

Zohar and Marshall (1994, 26), in a later publication, described spiritual intelligence as what

we address and solve problems of meaning and value, the intelligence with which we can place our actions and our lives in a wider, richer, meaninggiving context, the intelligence with which we can assess that one course of action or one life path is more meaningful than another.

This latter definition fits perfectly with the issues and challenges facing Africa today.

We argue that African policy-makers and public servants are facing critical issues surrounding meaning and values associated with the choices they make as custodians of public property. Therefore, the development of spiritual intelligence should help them improve on the decision and choices they make for the betterment of their humanness and the common good in line with the Ubuntu philosophy. In fact, it has been argued that, to be spiritually intelligent is to use what one knows in the right way, at the right time, in the right place, with the right intention (Chaudhary and Aswal 2013, 1510). Chaudhary and Aswal's explanation further buttresses our argument that developing spiritual intelligence rather than developing more professional and technical skills should be the focus of a new approach to building effective organizations in Africa. If African policy-makers and public servants can use their knowledge and skills in line with Chaudhary and Aswal's $(2013,1510)$ definition of spiritual intelligence, there will be significant positive difference in the economic and social condition of Africa. We argue that, for the level of its development, Africa has reasonable number of academically intelligent educated and professional people to make a huge positive difference to its current economic and social condition. What is lacking is a critical mass of spiritually intelligent policy-makers and public servants.

The foregoing explanation of spiritual intelligence also suggests that it is not the quantity of knowledge that matters, but the application of such knowledge within the context of meaning and value. This perspective on viewing knowledge is instructive to those wishing to transform the African mindset steeped in paper qualification to a mind-set based on demonstration of delivering something more meaningful. The "paper qualification" mind-set rather than the spiritual mind-set is responsible for selecting and assessing leaders based on the level of their academic qualifications, rather than what they have contributed or the potential to contribute. However, there are indications that things might be about to change in Nigeria at least. For example, the traditional method of selecting and promoting public senior servants which was based on academic achievements (i.e. written and academic tests) has now been jettisoned by the newly elected President renowned for his anti-corruption stance. In a recent statement to the newly promoted permanent secretaries, President Muhammadu Buhari states:

In keeping with the change mantra of this administration, the process for your selection as permanent secretaries was a departure from the previous practice of administering written and oral examinations. Instead, a more rigorous selection process, entailing vigorous screening of candidates' past records, potential and capacity for holding the office, integrity, honesty and sense of commitment was adopted, (Premium Times 2015)

The president further asserts:

This administration will not condone any excesses, indifference, incompetence, and corrupt practices in any form. Permanent secretaries are therefore advised to note these words of caution and disseminate them to all civil servants accordingly. If Nigeria has to realize its full potentials for greatness, its 
civil service must first understand and accept the "change mantra" of this Administration, and then lead its spread through all the institutions of governance and the economy (Premium Times 2015)

We believe the sustained success of the above approach adopted by the Nigerian government and indeed any government in Africa will depend on developing critical mass of spiritually intelligent people to act as policy-makers and public servants.

\section{Developing spiritual intelligence and Ubuntu qualities}

We argued that spirituality and Ubuntu are essential for developing effective people and organizations that can help address Africa's economic and social challenges. We also maintain that the current approach to the development of African policy-makers and public servants is ineffective and therefore requires adoption of new paradigm steeped in the philosophy of spirituality and Ubuntu. In this paper, we view Ubuntu and spirituality as complementary. Therefore, the techniques used to develop spiritual intelligence and Ubuntu qualities within organizational context should be complementary. It is worth noting that although the idea of using Ubuntu philosophy in education, training and development has been advocated and used widely, literature on how to develop Ubuntu qualities is still at its infancy (see Gano-Overway 2014; Jackson 2004; Malunga 2006). Therefore, much of what will be discussed in this section will be based on the literature on how to develop spiritual intelligence rather than how to develop Ubuntu qualities in an organizational setting.

King (1990) has identified four core cognitive abilities or capacities that constitute spiritual intelligence. The first is critical existential thinking where a person has the capacity to contemplate the nature of existential reality, the universe, space, time and existential issues. The second component is the cognitive ability to produce personal meaning and purpose from physical and mental experiences. The third component is the cognitive ability to identify transcendent dimensions of self, of others and of the physical world. The fourth component of spiritual intelligence is conscious state expansion. Here, it refers to the capacity to enter and exit higher states of consciousness. Developing spiritual intelligence therefore requires the acquisition of critical thinking using methods that enable people to think, reflect and contemplate on issues related to their purpose in life and how to live this purpose. This should then lead to the questioning of the meaning and value of their daily activities and the means of their livelihood. We do not advocate the use of King's (2007) third and fourth dimensions of spiritual intelligence in an African organizational setting because they fall within the realm of religious practices and they require specific competencies and skills to teach them. Most importantly perhaps, they can conflict with some religious beliefs.

Given that attaining spirituality or spiritual intelligence is a journey (Bigger 2008), experts argue that it is learned and enhanced by integrating the skills of emotional intelligence with spiritual qualities (Yurdakul, Ker-Dincer, and Akinci Vural 2008, 155). This is in tune with the argument that Ubuntu

AQ7 philosophy, principles and behavior are learned through child-rearing. According to experts, the needed qualities to increase spiritual intelligence include the identification of deepest values and a sense of meaning in life; practicing spiritual mindfulness. This refers to being conscious of the meaning and value of one's action at all times. This clearly requires practice and learning. The spiritual mindfulness should be integrated into daily lives (Yurdakul, Ker-Dincer, and Akinci Vural 2008; Zohar and Marshall 1994, 2000). Spiritual mindfulness can nourish intuitive wisdom, capacity for love, compassion, forgiveness, understanding, managing emotions and behavior, and living with zeal, dignity and empathy (Yurdakul, Ker-Dincer, and Akinci Vural 2008; Zohar and Marshall 1994, 2000). Developing these qualities will ensure the attainment of humanness as prescribed by Ubuntu philosophy (Mbigi 1997).

\section{Towards a foundation for spiritual and Ubuntu curriculum}

We argue that a good management and leadership program can enable people to acquire the desirable qualities of spirituality and Ubuntu which can help in the establishment of sound and effective institutions and organizations in Africa. A collection of work by several experts compiled by Pavlovich and Krahnke (2014) provides glimpses of how it is possible to help people acquire spiritual and Ubuntu qualities of empathy, caring and communitarianism. For example, Gano-Overway (2014) used Shutt's (1993) three-stage model to demonstrate how to enable coaches to apply the principles of Ubuntu (empathy and caring) as a means of developing young people. We believe similar model can be used to develop leaders and managers, which should enable them to acquire the qualities of spirituality and Ubuntu. The first stage is self-knowledge. Here we are referring to knowing self in relation to others. Understanding one's desires in relation to others. Understanding one's journey in relation to others. Understanding one's ultimate existence and destiny within the organization in relation to other members of the organization. This stage (self-consciousness) within the context of the organization should culminate in the total understanding of the interconnectedness of one with others. Interconnectedness of one's actions with other's actions, as well as its impact far beyond the organization and beyond short-term frame.

The second stage of the leadership and management development for imparting spirituality and Ubuntu is referred to as personal development of selfknowledge and self-affirmation (Gano-Overway 2014). This stage will allow leaders to confirm what they learnt about themselves in relation to others. They can do that through interaction with others in order to receive affirmation. Indeed, Ubuntu asserts that a person is a person through other persons (Gano-Overway 2013, 2014; Metz and Gaie 2010). To achieve humanness and spiritual attainment, one needs confirmation through feedback from 
others. While the first stage is largely theoretical in-class activity, the second stage is largely experiential social interaction where leaders and managers receive feedback regarding their behavior, decisions and actions. This stage will be an ongoing process akin to action learning.

The final stage should lead to a state where leaders and managers will be ready and comfortable to self-donate themselves to the organizations they serve and to the wider community to which they belong. This is possible when they are able to transcend their ego self and appreciate that the organization, the community and self are interconnected. In other words, the organization and the wider community is an extension of oneself in more ways than one. The well-being of one affects the well-being of the other. As Gano-Overway pointed out: "Ubuntu provides insight into how to live in community by developing solidarity, promoting mutual understanding, and building consensus regarding shared values and practices" (Gano-Overway 2014 , 170). In order to sustain the knowledge and behavior learnt, leaders and managers must be role models, coaches and teachers to the members of the organization. As it has been argued,

a person with Ubuntu engages in a myriad of relational practices in order to nourish and support other human beings, not for personal benefit or gain, but for the other person. Therefore, a structure to nurture includes developing caring personal relations, teaching Ubuntu to others, and practicing Ubuntu in one's community. (Gano-Overway 2014, 170)

\section{Integrating spiritual principles into organizational roles}

To transfer spiritual intelligence and Ubuntu qualities into roles and performance, it is essential to use a framework for understanding the basic competencies required to perform any job role within an organization. Gill (2003) has identified four dimensions of skills and intelligence required to perform leadership roles which we believe are also required to perform any role in a spiritually based organization. The first dimension is the intellectua/cognitive dimension of competence. This relates to thinking or the ability to see and comprehend what is required to be done. This is 'the electoral or cognitive ability to perceive and understand information, reason with it, imagine possibilities, use intuition, make judgements, solve problems and make decisions" (Gill 2003). According to Gill (2003 , 311), these abilities produce vision, mission (purpose), shared values and strategies for pursuing the vision and mission that win people's mind. We argue that these abilities lie within the framework of developing technical and professionalmanagerial skills, which has been well articulated, developed and used in contemporary organizations, but underpinned by Western philosophy and principles. While we see the utility of using this dimension of skills in African organizations, but it should be underpinned by the philosophy and principles of spirituality and Ubuntu. For example, organizational vision and purpose should be articulated within the context of communalism and interconnectedness.

The second dimension of skills and competencies is the ability to make meanings that are shared with the members of the organization. This is the spiritual dimension of leadership (Gill 2003). The author cited Dess and Picken (2000), saying that Xerox PARC guru pointed out that "the job of leadership today is not just to make money; it's to make meaning". (Gill 2003, 311). This clearly suggests that helping public servants to develop a sense of purpose and meaning should be a key aspect of training and development, rather than focusing on technicalprofessional skills. The philosophy and principles of spirituality and Ubuntu should underpin how leaders define the purpose of the organization and how they articulate the meaning they create. The third dimension of leadership role that requires specific skills relates to skills in undertaking the tasks enshrined in the role. This refers to skills and competencies in doing (Gill 2003). We argue that within the context of spirituality and Ubuntu, competence and skills is not detached from ultimate purpose. In other words, it is the purpose that should determine and judge whether a person is competent or skilful rather than a predetermined and codified proficiency in sets of activities. Therefore, the person should be emotionally in tune with the impact and potential impact of his/her actions rather than just mechanically going through predetermined and codified set of motions as typified in the Western-based approach to competencies and skills. This new approach requires the possession of emotional intelligence to act in a spiritually appropriate way.

Finally, the final dimension of skills and competencies required to be included in a training and development curriculum of policy-makers and public servants is emotional intelligence skills. As Gill $(2003,311)$ pointed out, emotional intelligent leaders need to understand themselves and others, display self-control, display self-confidence and respond to others in an appropriate way. What is appropriate in the context of this paper should be guided by the philosophies and principles of Ubuntu and spirituality which are based on the notion of humanness. In fact

To become a leader you must first become a human being, according to the Confucian philosophy of traditional Chinese culture. This simple statement expresses a timeless notion that developing as a leader is a lifetime journey of cultivating our capacity to see and sense what is needed for the whole. (Senge and Krahnke 2014, 199)

\section{Techniques for spiritual development}

The framework advanced above will set the foundation for developing leaders and managers to attain spirituality and Ubuntu states. The framework can be deployed using multiple techniques which have been tried and tested by social psychologists, personal development experts and trainers in various 
fields. Central to the idea of spirituality and Ubuntu is the notion of connectedness. One of the human qualities that can enable an individual to see and practice interconnectedness is empathy. Several experts have developed techniques for developing empathy (Atkins 2014; Ciarrochi and Mayer 2007; Coulehan et al. 2001; Glomb et al. 2011; Goleman 2006; Mazutis and Slawinski 2008). Indeed, Pavlovich and Krahnke (2014, 1) see "empathy as the capacity to experience and relate to the thoughts, emotions, and experience of others and involves a heightened awareness of others". Based on this description, it is clear that if African policy-makers and public servants can develop a high and sustainable level of empathy, they will be able to practice most of the principles of spirituality and Ubuntu. Empathy will at the very least enable them to practice compassion, sympathy, humility and connectedness. These four qualities should enable them to carry out their roles with integrity, sacrifice and selflessness. More specifically, empathy will enable them to see how their decisions will affect others and how others might feel. The sympathy and compassion to be generated by empathy should enable African policy-makers and public servants to make the appropriate choices in resource distribution and the protection of public property for the common good. This is because experts have argued that psychological maturity is demonstrated by transcending self-identity and gaining unity with others (Heaton 2011; Heaton and Travis 2014). Leaders who are able to develop empathy must have passed through ego development where they feel the pain of others, whether the pain was inflicted by them through their decisions and actions as leaders or by the decision and actions of others. Leadership and management training programs in Africa do not focus on ego development, but rather on professional and technical skills regarding how to run an efficient organization. This approach is based on neoliberal western philosophy which is inappropriate to the economic and social conditions of Africa (Zohar 2005).

One of the techniques for developing empathy is transcendental meditation (TM) (Heaton and Travis 2014). Heaton and Travis (2014) have reported several studies that demonstrated the positive relationship between TM and the development of empathy and general well-being. A technique similar to TM can be used in leadership and management development, with the aim of producing leaders steeped in the philosophy of spirituality and Ubuntu. Through the technique, leaders should be able to go deeper into their inner self and find peace and unity with others. There are three types of meditative practices that have been used to develop empathy leading to unity with others. The first is focus on concentrating on an object. The second is purposeful attention to whatever enters the field of awareness (Kristeller and Johnson 2005, 395). The third "is a directed meditation where the content is important and is there to engage a certain part of the self, but in a mindful rather than judgemental way" (Berry and Joannides 2014, 39). As we stated earlier, empathy will lead to spiritual quality of connectedness, compassion and kindness. As Pavlovich and Krahnke (2012, 136) pointed out “empathy is the force that makes a community whole through recognizing the interconnectedness and interdependencies among us rather than it merely being a collection of individuals". Also Berry and Joannides $(2014,39)$ pointed out, "People with a high degree of empathy will tend to help others without regard for any personal gain. Transcending the needs of the self and experiencing empathy will lead to connectedness and loving kindness". Given the sensitivity to religious practices in Africa, we are not advocating the whole sale use of TM. Instead, we are challenging trainers and experts to use TM techniques to develop A frocentric technique for developing empathy.

Another technique that can be used to achieve spirituality and Ubuntu qualities through empathy is mindfulness training (Atkins 2014). Mindfulness is a training technique which allows trainees to purposely pay attention to present experiences without judgment or reference to past or future experience (Atkins 2014; Glomb et al. 2011). Mindfulness should enable policy-makers and public servants to observe their thoughts and feelings pertaining to the decisions or action they are about to take (Hayes and Plumb 2007). To the extent that mindfulness is fully developed, we argue that it can be a powerful tool against selfish decisions and actions. This is because many decisions and actions are taken without "mindfulness". People tend to reflect on their decisions and actions and either regret or rationalize them. Mindfulness should enable the decision-maker to be conscious and observe the decisionmaking in process. This should provide the opportunity to consciously imagine and experience the consequences of the decision here and now.

Another technique that can help in the attainment of spirituality and Ubuntu through empathy is the development of skills in emotional identification, emotional understanding and emotional management (Atkins 2014, 59). Emotional skills allow individuals to have self-control in the face of temptations. Much of the selfish behaviors by African policy-makers and public servants can be restrained if they are able to check the temptations to use public property or to exclude some sections of the society in favor of their own tribes, religion or region. We believe many, if not most, of the corrupt people would prefer to behave in a manner that befits their oath of office. However, they do not have the skills to control their emotions when faced with external AQ8 stimuli that triggers nepotism and self-gratification. Researchers have demonstrated that Goleman's (2006) four domains of emotional intelligence can be developed through multiple techniques (Nelis et al. 2009). The four domains are self-awareness, self-management, social awareness and relationship management.

\section{Rationale for adopting a spiritual approach to institution building and leadership development}

Experts argue that people can have or develop spiritual traits (Emmons 2000; Thompson 2000) or intelligence (Zohar 2005; Zohar and Marshall 2000 ). Spiritual traits have been argued to lead to desirable behavior; indeed, the last two decades have seen growing interest in spirituality within 
organizations (Karakas 2010; King 1999; Mitroff and Denton 1999a; Neal, Bergmann Lichtenstein, and Banner 1999). For example, Neal, Bergmann Lichtenstein, and Banner (1999) advocate that management scholars should incorporate spirituality into research and theory building, and their call has, to some extent, been heeded. Researchers have investigated the impact of spirituality on organizational productivity and performance, profitability and success (Delher and Welsh 1994; Konz and Ryan 1999; Mitroff and Denton 1999b). This paper adopts Banner and Gagne's (1995) and Neal, Bergmann Lichtenstein, and Banner's (1999) model of transformation to argue for a way in which African social and economic challenges can be addressed through building effective public institutions and organizations, and engendering leaders with spiritual intelligence. The model assumes that individual and society are interconnected. The building blocks of society are the individuals who co-create the life they find themselves in (Banner and Gagne 1995). Neal et al. argue that

By identifying causality at the level of shared beliefs, attitudes, and values, there is recognition that when enough individuals make the shift to a new paradigm and as more and more organizations do also there is higher likelihood that society will transform as well. This social transformation then is not based on an overarching economic benefit to the culture, but on the realized shifts in individuals and organizations as they become more attuned to spiritual principles and issues. (1999: 180)

Central to our argument in this paper, therefore, is that Africa needs to produce a critical mass of policy-makers and implementers steeped in the principles of spirituality and Ubuntu. These core public office holders should be the change agents that will lead to the transformation of the African social and economic condition, ravaged as it is by corruption and social conflict. The framework (Diagram 1) advanced in this paper assumes that while professional training is vital for developing the people required to run effective African institutions and organizations, the exclusive focus on professional (technical) aspects has proven to be inadequate for eliciting the desired behavior required. The new approach is necessary to ensure that leaders and policy actors apply the knowledge and skills they have acquired.

Diagram 1. Framework for professional (technical) and personal (spiritual) training and development of leaders and policy actors (Makers \& Implementers).

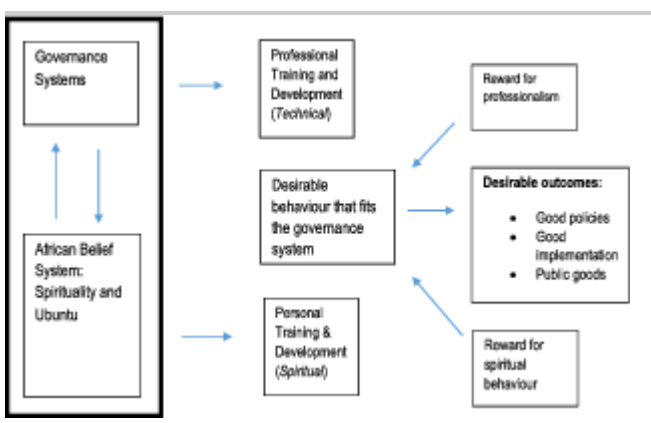

\section{Embedding spirituality into African institutions and organizations}

We argue that in order to deliver their mandate effectively, African institutions and organizations will need to have the doctrine of spirituality and Ubuntu running through their veins. This means that spirituality and Ubuntu should be embedded into the: (1) vision; (2) mission; (3) strategy; and (4) operation of institutions and organizations. Table 1 provides a summary of how this can be achieved.

Table 1. Embedding spirituality into African public institutions and organizations.

\begin{tabular}{|l|l|l|}
\hline $\begin{array}{l}\text { Key } \\
\text { elements }\end{array}$ & Description & Explanation \\
\hline Vision & $\begin{array}{l}\text { Spiritual dream where the organization or institution sho } \\
\text { uld ideally be within the context of communalism and in } \\
\text { terconnectedness }\end{array}$ & $\begin{array}{l}\text { There should be spiritual audit that determines the extent to which the organization lives by spiritual and Ubuntu ideals. The outcome should form } \\
\text { the foundation upon which the organization builds its identity as a spiritual entity }\end{array}$ \\
\hline Mission & $\begin{array}{l}\text { Spiritual statement on why the organization or institutio } \\
\text { nexists and who it serves. This means that the organizat } \\
\text { ion should be viewed as a communal enterprise (Lutz } 20 \\
09)\end{array}$ & $\begin{array}{l}\text { There should be clear articulation of why the organization exists and how it relates to the community and society at large. There should be clear un } \\
\text { derstanding that its survival depends on the survival of society }\end{array}$ \\
\hline Strategy & $\begin{array}{l}\text { Spiritual philosophy that guides the decisions and behav } \\
\text { ior of leaders of the organization and institutions }\end{array}$ & $\begin{array}{l}\text { Policy-makers and leaders should be guided by the ideals of spirituality and Ubuntu when making strategic decisions. Their behaviors both on and } \\
\text { off the job should be models for members of the organization and the community }\end{array}$ \\
\hline $\begin{array}{l}\text { Operatio } \\
\mathrm{n}\end{array}$ & $\begin{array}{l}\text { Spiritual guidelines on what and how in relation to what } \\
\text { every member of the organization and institution should } \\
\text { do and how they do it }\end{array}$ & $\begin{array}{l}\text { All organization members should have a clear understanding of why they are there, what they are expected to do, the significance of their role within } \\
\text { the context of spiritual organizations, and how they should conduct themselves. Jobs should be designed to provide meaning to the job holder. Irres } \\
\text { pective of where people are on the organizational hierarchy, people should see and experience connection with the purpose of the organization }\end{array}$ \\
\hline
\end{tabular}

\section{Embedding spirituality into the people management system}

The issue of the transfer of learning has always been a challenge to training and development programs, especially in Africa. We argue that personal development programs which focus on spirituality will act as a strong motivator for transferring what is learnt from professional development programs. 
However, professional and spiritual training and development will not guarantee transfer of learning (desirable behavior) without an embedded system of rewards or incentives to sustain the application of knowledge and skills acquired from the training and development programs. The incentive or reward must be adequate to prevent policy-makers and policy actors from taking alternative courses of action, such as engaging in unspiritual and unprofessional behavior. Adequacy of incentive should be measured in terms of quality, not quantity. Thus, there should be a strong culture that acknowledges and reprimands unprofessional and unspiritual behavior. The doctrine of spirituality and professionalism should be embedded in the organizational strategy, policy and practice, as well as in the systems of reward and recognition. People should be recognized not only for their professional behavior, but also for their spiritual behavior. Human resource management systems, from workforce planning, recruitment and selection to retirement/resignation/dismissal, should have a professional and spiritual dimension embedded within them. Table 2 provides indicative guidelines on how to develop a spiritually based human resource management system.

Table 2. Embedding spirituality into the people management system.

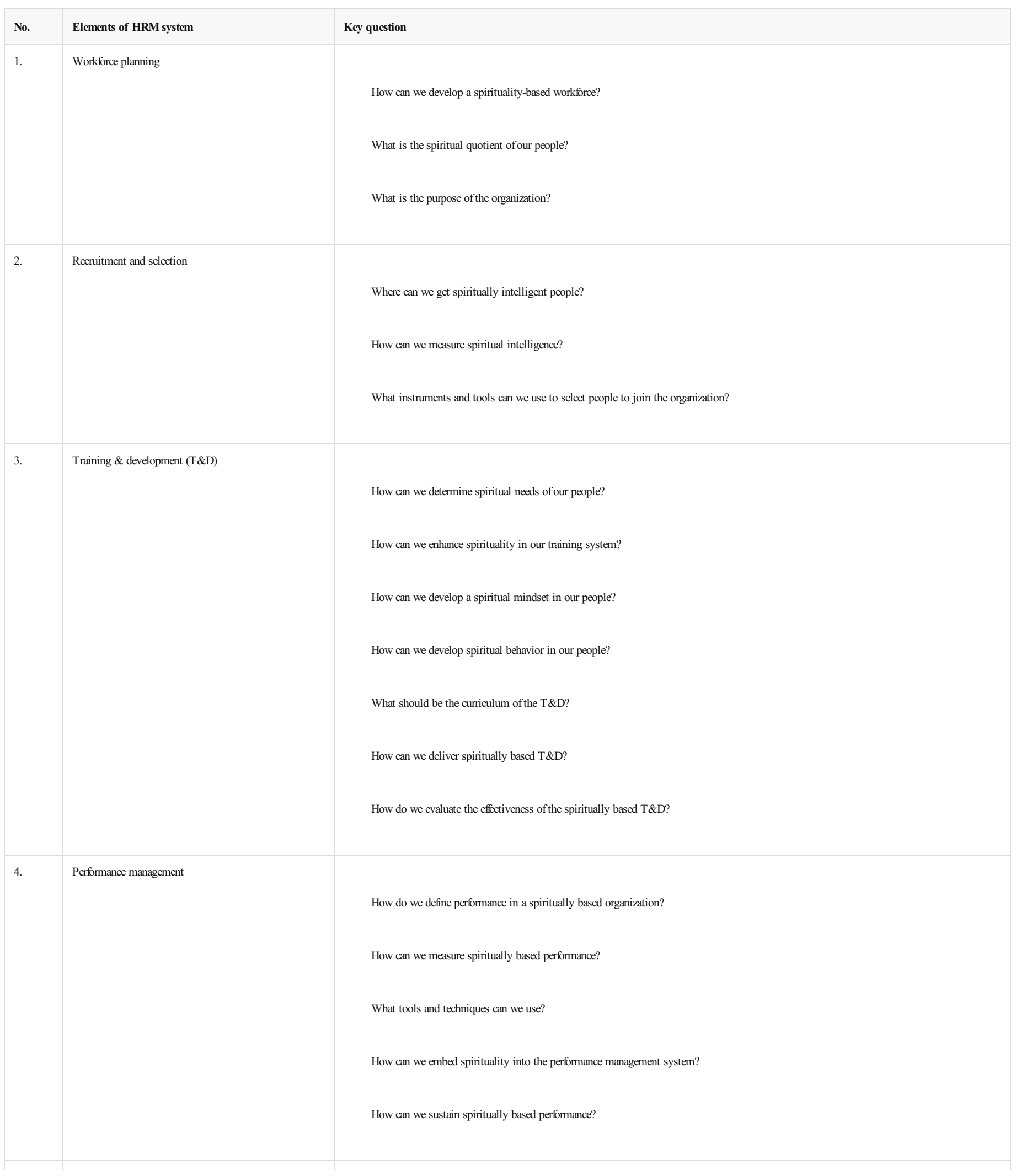




\section{Conclusion}

It is widely argued that institutions and organizations are the building blocks of modern societies. However, African nations are characterized by an institutional void and ineffective organizations. In fact, given the social challenges facing the continent today, even the effectiveness of informal institutions such as customs and traditions are brought into question. Social conflicts that used to be settled through customs and traditions are now settled through violence in many instances. Therefore, this paper sets out to provide a novel approach for building effective institutions and organizations which can mitigate the social and economic challenges facing the continent today. We advance the concept of spirituality and Ubuntu as the foundation on which to build effective organizations and leaders. Similarly, we argue for the use of spirituality in the training and development of policy-makers and leaders of key institutions and organizations in Africa. To effect the necessary changes in organizations and institutions, the paper advocates and recommends the transformation of the current organizational and human resource management systems and the establishment of spiritually based systems.

This paper is both conceptual and practical, in the sense that it provides a novel idea for building effective individuals and organizations backed up by practical guidelines. Our approach is novel and creative within the African context, for the following reasons: first, the copy and paste approach to building institutions and organizations appears to have run its course with the advent of economic and social challenges brought about by globalization. Policy-makers, leaders, institutions and organizations are increasingly finding it difficult to keep step with social and economic challenges facing Africa today. Second, the emphasis on professional and technical skills - which are devoid of humanistic, communal and cultural context - has robbed African policy-makers and leaders of the qualities desperately needed to deliver and implement the public policies that will mitigate the social and economic challenges of the continent. Although Ubuntu philosophy and certainly some of its principles overlap with some Western and Eastern philosophies and principles (Lutz 2009), Ubuntu is perhaps more likely to succeed as a foundation for transforming African organizations and their members because most Africans live by some of the principles in their daily lives, even though some might not be consciously aware. Therefore, less effort is required to get people to internalize the principles of Ubuntu compared to the effort required to adopt foreign philosophy and principles. In fact, in spite of the colonial legacy of Western philosophy and principles, many Africans have adopted Western behavior but failed to adopt and internalize Western philosophy and principles when running a modern organization.

Finally, the traditional African belief system is compatible with the ideals of spirituality. Indeed, spirituality as defined and advocated in this paper, is compatible with social and economic development of Africa as well as with the sustainability of harmony amongst diverse belief systems (religions), ethnicity, tribes and races typical of the African continent. We therefore hope that the ideas advanced in this paper will ignite interest in researching the

AQ9 use of spirituality to build effective individuals, organizations and institutions in Africa.

\section{References}

Africa Commission Report. 2005. Our Common Interest. London: Office of the Prime Minister, March 2005.

Apter, M. J. 1985. "Religious States of Mind: A Reversal Theory Interpretation.” In Advances in the Psychology of Religion, edited by L. B. Brown, AQ10 62-75. Oxford, NY: Pergamon page.

Atkins, P. W. B. 2014. 'Empathy, Self-other Differentiation and Mindfulness Training.” In Organizing through Empathy, edited by K. Pavlovich and K. Krahnke, 49-69. London: Taylor Francis.

Banner, D., and E. Gagne. 1995. Designing Effective Organizations: Traditional and Transformational Views. Thousand Oaks, CA: Sage.

Bengu, M. J. 1998. Ubuntu: The Essence of Democracy. Cape Town: Novalis.

Berry, D. H., and V. Joannides. 2014. “The Sources of Empathy in Our Lives.” In Organizing through Empathy, edited by K. Pavlovich and K. Krahnke, 34 48. London: Taylor Francis. 
Bigger, S. 2000. "Spiritual and Religious Education and Antiracism." In Values in Education and Cultural Diversity, edited by M. Leicester, S. Mogadil, and C. Mogadil, 15-24. London: Routledge Faimer.

Bigger, S. 2008. “Secular Spiritual Education?” Education Futures 1 (1): 60-70.

Broodryk, J. 2005. Ubuntu Management Philosophy. Randburg: Knowres, 168

Chabal, P. 2002. “The Quest for Good Government and Development in Africa: Is NEPAD the Answer?” International Affairs 78 (3): $447-462$.

Chaudhary, B., and M. Aswal. 2013. “Imparting Spiritual Intelligence Curriculum in Our Classrooms.” European Academic Research 1 (7): $1508-1515$.

AQ11 Ciarrochi, J., and J. D. Mayer 2007. Applying Emotional Intelligence. A Practitioner's Guide Xiv. NY: Psychology Press, 169.

Coulehan, J. L., F. W. Platt, B. Egener, R. Frankel, C. T. Lin, B. Lown, and W. H. Salazar. 2001. ““Let Me See If I Have This Right ...”: Words That Help Build Empathy." Annals of Internal Medicine 135 (3): 221-227.

Crick, B. 1999. “The Presuppositions of Citizenship Education.” Journal of the Philosophy of Education 33 (3): 337-352.

AQ12 Damane, M. B. 2001. “Executive Commentary.” Academy of Management Executive 15 (3): 34.

Delher, G., and M. Welsh. 1994. "Spirituality and Organizational Transformation: Implications for the New Management Paradigm" Journal of Managerial Psychology 19 (6): 17-26.

Deng, F. N., and T. Lyons 1998. 'Promoting Responsible Sovereignty in Africa.” In Africa Reckoning: A Quest for Good Governance, edited by AQ13 Deng and Lyons, 1. Washington, DC: Brooking Instituion.

Dess, G. G., and J. C. Picken. 2000. “Changing Roles: Leadership in the 21st Century.” Organizational Dynamics 28 (3): 18-34.

Dzobo, N. K. 1992. “The Images of Man in Africa.” In Person and Community: Ghanaian Philosophical Studies, edited by K. Wiredu and K. Gyeke, 137-152. Washington, DC: The Council of Research in Values and Philosophy.

Emmons, R. A. 1999. 'Religion in the Psychology of Personality: An Introduction.” Journal of Personality 67: 873-888.

Emmons, R. A. 2000. 'Is Spirituality an Intelligence? Motivation, Cognition, and the Psychology of Ultimate Concern.” International Journal for the AQ14 Psychology of Religion 10 (3): 26.

Gano-Overway, L. A. 2013. "Exploring the Connections between Caring and Social Behaviors in Physical Education.” Research Quarterly for Exercise and Sport 84 (1): 104-114.

Gano-Overway, L. A. 2014. “The Caring Climate: How Sport Environment Can Develop Empathy in Young People.” In Organizing through AQ15 Empathy, edited by K. Pavlovich and K. Krahnke, 167-183. Taylor Francis.

George, L. K., D. B. Larson, H. G. Koenig, and M. E. McCullough. 2000. "Spirituality and Health: What We Know, What We Need to Know." Journal of Social and Clinical Psychology 19 (1): 102-116.

Gill, R. 2003. “Change Management - Or Change Leadership?” Journal of Change Management 3 (4): 307-318.

Glomb, T. M., M. K. Duffy, J. E. Bono, and T. Yang. 2011. “Mindfulness at Work.” Research in Personnel and Human Resource Management 30: $115-157$.

AQ16 Goleman, D. 2006. Working with Emotional Intelligence. NY: Bantam, Dell.

Gyekye, K. 1996. The Unexamined Life: Philosophy and the African Experience. Accra: Sankofa.

Hayes, S. C., and J. C. Plumb. 2007. 'Mindfulness from the Bottom Up: Providing an Inductive Framework for Understanding Mindfulness Processes and their Application to Human Suffering." Psychological Inquiry 18 (4): 242-248. 
Heaton, D. P. 2011. 'Transcendent Experience and Development of the Post-representation Self.' In The Post Conventional Personality: Perspectives on Higher Development, edited by A. Pfaffenberger, P. Marko, and A. Combs, 175-188. Albany, NY: SUNY Press.

Heaton, D. P., and F. Travis. 2014. "Consciousness Empathy and the Brain.” In Organizing through Empathy, edited by K. Pavlovich and K. Krahnke, 17-33. London: Taylor Francis.

Jackson, T. 2004. Management and Change in Africa. London: Routledge.

Jaworski, J. 1996. Synchronicity: The Inner Path of Leadership, San Francisco, CA: Berrett Koehler.

July, R. W. 2004. The Origins of Modern African Thought. Trenton: Africa World Press.

Kamalu, C. 1990. Foundation of African Thought: A Worldview Grounded in the African Heritage of Religion, Philosophy, Science and Art. London: Karnak House.

Karakas, F. 2010. "Spirituality and Performance in Organizations: A Literature Review.” Journal of Business Ethics 94 (1): 89-106.

Karsten, L., and H. Illa. 2005. 'Ubuntu as a Key African Management Concept: Contextual Background and Practical Insights for Knowledge Application.” Journal of Managerial Psychology 20 (7): 607-630.

King, S. 1990. Urban Shaman: A Handbook for Personal and Planetary Transformation Based on the Hawaiian Way of the Adventurer. NY: AQ17 Simon and Schuster.

King, S. 1999. "Organizational Enhancement through Recognition of Individual Spirituality.” Journal of Organizational Change Management 12: 234-243.

Konz, G., and F. Ryan. 1999. "Maintaining an Organizational Spirituality: No Easy Task.” Journal of Organizational Change Management 12 (3): 200-210.

Kristeller, J. L., and T. Johnson. 2005. "Cultivating Loving Kindness: A Two-stage Model of the Effects of Meditation on Empathy, Compassion, and Altruism. Zygon 80 (2): 391-408.

Lutz, D. 2009. “African Ubuntu Philosophy and Global Management.” Journal of Business Ethics 84 (S3): 313-328.

Makuvaza, N. 1996. 'Literature Sources: Hunhuism or Ubuntuism: A Zimbabwean Indigenous Political Philosophy (by T Samkange and S Samkange (1980)).” Zimbabwe Journal of Education Research 8 (1): 75-77.

Malunga, C. 2006. Learning Leadership Development from African Cultures: A Personal Perspective. Praxis Note No: International NGO Training and Research Centre; INTRAC. 25.

Mangaliso, M. P. 2001. 'Building Competitive Advantage from Ubuntu: Management Lessons from South Africa." Academy of Management Executive 15 (3): 23-33.

Mazutis, D., and N. Slawinski. 2008. “Leading Organizational Learning through Authentic Dialogue.” Management Learning 39 (4): $437-456$.

Mbigi, L. 1997. Ubuntu: The African Dream in Management. Johannesburg: Knowledge Resources.

AQ18 Mbiti, J. S. 1991. African Religions and Philosophy. 2nd ed. NH: Heinemann.

Metz, T. 2007. “Toward an African Moral Theory.” The Journal of Political Philosophy 15 (3): 331-334.

Metz, T., and J. B. R. Gaie. 2010. “The African Ethic of Ubuntu/Botho: Implications for Research on Morality.” Journal of Moral Education 39: 273-290.

Mitroff, I., and E. A. Denton. 1999a. “A Study of Spirituality in the Workplace.” Sloan Management Review 40 (4): $83-92$.

Mitroff, I., and E. Denton. 1999b. A Spiritual Audit of Corporate America: A Hard Look at Spirituality, Religion, and Values in the Workplace. San Fransisco, CA: Jossey-Bass. 
Neal, J. A., B. M. Bergmann Lichtenstein, and D. Banner. 1999. "Spiritual Perspectives on Individual, Organizational and Societal Transformation." Journal of Organizational Change Management 12 (3): 175-186.

Nelis, D., J. Quoidbach, M. Mikolajczak, and M. Hansenne. 2009. 'Increasing Emotional Intelligence: (How) is it Possible?’ Personality and Individual Differences 47 (1): 36-41.

Nkondo, G. M. 2007. "Ubuntu as Public Policy in South Africa: A Conceptual Framework.” Internation Journal of African Renaissance Studies 2: 88-100. doi:10.1080/18186870701384202

Nussbaum, B. 2003. "African Culture and Ubuntu: Reflections of a South African in America.” Perspectives 17 (1): 1-12.

Nziramasanga, T. 1999. Report of the Presidential Commission of Inquiry into Education and Training. Harare: CDU.

Obiora, F. I., and N. N. Edozien. 2001. Understanding Africa: Traditional Legal Reasoning, Jurisprudence and Justice in Igboland. Enugu: CIDJAO.

Pargament, K. I., and C. L. Park. 1995. 'Merely a Defense? The Variety of Religious Means and Ends.” Journal of Social Issues 51:13-32.

Pavlovich, K., and K. Krahnke. 2012. “Empathy, Connectedness and Organisation.” Journal of Business Ethics 105: 131-137.

AQ19 Pavlovich, K., and K. Krahnke, eds. Organizing through Empathy. London: Taylor Francis, 1

Premium Times. 2015. How I Bent the Rule in Appointing Perm Secs - Buhari,

November 12

. http $/ /$ www.premiumtimesng.com/news/headlines/193075-\%E2\%80\%8Bhow-i-bent-the-rule-in-appointing-perm-secs- $\% \mathrm{E} 2 \% 80 \% 8 \mathrm{Bbuhari.html}$

Ramose, M. B. 1999. African Philosophy through Ubuntu. Harare: Mount.

Roehlkepartain, E. C., P. E. King, L. Wagener, and P. L. Benson. 2006. The Handbook of Spiritual Development in Childhood and Adolescence. London: Sages.

Samkange, S., and T. Samkange. 1980. Hunhuism or Ubuntuism: A Zimbabwean Indigenous Political Philosophy. Salisbury: Graham.

Senge, P., and K. Krahnke. 2014. “Transcendent Empathy: The Ability to See the Larger System.” In Organizing through Empathy, edited by K. Pavlovich and K. Krahnke, 185-202. London: Taylor Francis.

Shutte, A. 1993. Philosophy for Africa. Milwaukee, WI: Marquette University Press.

Shutte, A. 2001. Ubuntu: An Ethic for the New South Africa, 24. Cape Town: Cluster.

Sibanda, P. 2014. 'The Dimensions of 'Hunhu/Ubuntu'(Humanism in the African Sense): The Zimbabwean Conception.” IOSR Journal of Engineering 4 (1): 26-29.

Swanson, D. M. 2007. 'Ubuntu: An African Contribution to (Re)Search for/with a 'Humble Togetherness'.” Journal of Contemporary Issues in Education 2 (2): 53-67.

Thompson, W. D. 2000. “Can You Train People to Be Spiritual?” Training and Development 54 (12): 18-19.

Turner, M., D. Hulme, and W. McCourt. 2015. Governance, Management and Development: Making the State Work. London: Palgrave.

AQ20 World Bank. 2009. Global Monitoring Report: A Development Emergency. Washington, DC.

AQ21 World Bank. 2013. World Development Report: Jobs. Washington, DC.

Yurdakul, N., M. Ker-Dincer, and Z. B. Akinci Vural. 2008. "Searching for Excellence in Educational Communication: The Role of IQ." EQ and SQ. Bilig 45: 147-164. 
Zinnabauer, B. J., K. I. Pargament, B. J. Cowell, M. Rye, and A. B. Scott. 1997. "Religion and Spirituality: Unfuzzing the Fuzzy." Journal for the Scientific Study of Religion 38: 412-425.

Zohar, Danah. 2005. “Spiritually Intelligent Leadership.” Leader to Leader 2005 (38): 45-51.

Zohar, D., and I. Marshall. 1994. Quantum Society: Mind, Physics and a New Social Vision. New York: William Morris and Company.

Zohar, D., and I. Marshall. 2000. SQ: Spiritual Intelligence, the Ultimate Intelligence. New York: Bloomsbury Press. 